\title{
FARKLI YÖNTEMLERLE ACILIĞI GİDERİLMİŞ LÜPEN UNU VE DİRENÇLİ NIŞASTA İÇEREN EKMEKLERİN KALİTE ÖZELLİKLERİ ÜZERİNE VİTAL GLUTEN VE EMÜLGATÖRÜN ETKİSİ
}

\author{
Elif Yaver, Nermin Bilgiçli* \\ Necmettin Erbakan Üniversitesi, Mühendislik ve Mimarlık Fakültesi, Gıda Mühendisliği Bölümü, Konya, Türkiye \\ Geliş / Received: 07.11.2020; Kabul / Accepted: 11.01.2021; Online bask1 / Published online: 18.01.2021
}

Yaver, E., Bilgiçli, N. (2021). Farklı yöntemlerle acıllğı giderilmiş lüpen unu ve dirençli nişasta içeren ekmeklerin kalite özellikleri üzerine vital gluten ve emülgatörün etkisi. GIDA (2021) 46 (2) 243-255 doi: 10.15237 /gida. GD20128.

Yaver, E., Bilgiçli, N. (2021). Effect of vital gluten and emulgator on quality properties of bread containing lupin flour debittered by different methods and resistant starch. GIDA (2021) 46 (2) 243-255doi: 10.15237/gida. GD20128.

\section{ÖZ}

Bu çalışmada; ekmeğin besinsel özelliklerini geliştirmek için ekmek üretiminde kullanılan buğday unu, farklı metotlarla (geleneksel ve ultrason uygulamalı) acilı̆̆ giderilmiş lüpenden elde edilen un (\%10) ve tip4 dirençli nişasta (DN-\%10) ile yer değiştirilmiştir. Ekmeğin kalite özelliklerini geliştirmek amacıyla vital gluten ve/veya sodyum stearol-2-laktilat (SSL) ilavesi yapılarak, katk1 maddelerinin ekmek kalitesi üzerine etkileri belirlenmiştir. Ekmek formülasyonuna lüpen unu+DN ilave edilmesiyle azalan hacim ve spesifik hacim değerleri, katkı maddelerinin kullanımı ile yükselmiştir. Ultrason uygulamasıyla acilığ giderilmiş lüpen unu kullanımı; geleneksel yöntemle acıllğı giderilmiş lüpen unu içeren ekmeklere göre daha yüksek hacim ve spesifik hacim ile daha düşük sıkılık ve sertlik değerleri sağlamıştr. Vital gluten+SSL kombinasyonu ile üretilen ekmeklerin sertlik, elastikiyet, koheziflik ve esneklik değerleri istatistiki açıdan buğday unu ekmeğine benzer bulunmuştur $(P>0.05)$. Ekmek örneklerinin genel beğeni puanları \%10 lüpen unu+\%10 DN kullanımı ile azalmıs, vital gluten ve vital guten+SSL ilavesi genel beğeni puanlarının buğday unu ekmeğine yakın olmasını sağlamıştur.

Anahtar kelimeler: Vital gluten, sodyum stearol-2-laktilat (SSL), lüpen, dirençli nişasta, ekmek

\section{EFFECT OF VITAL GLUTEN AND EMULGATOR ON QUALITY PROPERTIES OF BREAD CONTAINING LUPIN FLOUR DEBITTERED BY DIFFERENT METHODS AND RESISTANT STARCH}

\begin{abstract}
In this study, wheat flour used in bread was replaced by flour $(10 \%)$ obtained from lupin debittered by different methods (traditional and ultrasound application) and resistant starch type4 (RS-10\%) to improve nutritional properties of bread. The effects of vital gluten and/or sodium stearoyl-2-lactylate (SSL) on quality characteristics of bread were investigated. While volume and specific volume decreased with addition of lupin flour+RS to bread formulation, it increased with additives. Use of lupin flour debittered by ultrasound provided higher volume and specific volume, lower firmness and hardness compared to breads containing lupin flour debittered by traditional method. Hardness, springiness, cohesiveness and resilience of breads produced with vital gluten+SSL were found
\end{abstract}

\footnotetext{
${ }^{*}$ Yazışmalardan sorumlu yazar / Corresponding author

17: nerminbil2003@hotmail.com,

(ग): (+90) 3323237926

鸟: (+90) 3322362141
}

Elif Yaver; ORCID no: 0000-0002-2651-9922

Nermin Bilgiçli; ORCID no: 0000-0001-5490-9824 
statistically similar to wheat flour bread $(P>0.05)$. Overall acceptability scores of breads decreased with use of $10 \%$ lupin flour $+10 \%$ RS, addition of vital gluten or vital gluten+SSL provided overall acceptability scores close to wheat flour bread.

Keywords: Vital gluten, Sodium stearoyl-2-lactylate (SSL), lupin, resistant starch, bread

\section{GİRIŞ}

Antik bir baklagil tanesi olarak bilinen lüpen (Lupinus albus L.), Akdeniz çevresinde, Balkanlar, Asya, Avrupa ve Güney Amerika'da yetiştirilmektedir. Proteince zengin (\%33-47) bir bileşime sahip olan lüpen aynı zamanda; diyet lifi, yağ, $\alpha$-tokoferol, tiamin, riboflavin, $C$ vitamini ve çeşitli mineraller içermektedir (Dervas vd., 1999; Mohammed vd., 2017). Bununla birlikte, lüpen yüksek oranda antioksidan aktiviteye ve fenolik madde içeriğine sahiptir (Oomah vd., 2006). Lüpenin insan sağllğı üzerine etkilerinin araştırldığ1 çalışmalarda; düşük yoğunluklu lipoprotein seviyesi, plazma kolesterolü ve trigliseritler ile kan basıncında azalma sağladığı, kardiyovasküler hastalık riskini düşürdüğü bildirilmiştir (Sirtori vd., 2004; Lee vd., 2009; Belski vd., 2011). Lüpen içeriği yüksek olan gıdalar, glisemik indeksinin düşük olması sebebiyle diyabet ve obezitenin kontrolünde kullanılabilmektedir (Johnson vd., 2003).

Dirençli nişasta (DN), üst gastrointestinal sistemde 120 dakika boyunca hidrolize direnç gösteren nişastadır. DN, postprandiyal hiperglisemiyi etkilememektedir. Kalın bağırsakta mikroorganizmalar tarafindan fermente edilen DN, kısa zincirli yağ asitlerine (bütirat, propiyonat ve asetat gibi) ve çeşitli gazlara $\left(\mathrm{CO}_{2}, \mathrm{CH}_{4}\right.$ ve $\left.\mathrm{H}_{2}\right)$ dönüştürülmektedir (Englyst vd., 1992). Kalın bağırsaktaki kısa zincirli yağ asitleri; kardiyovasküler hastalıklar, inflamatuar bağırsak hastalığ1 ile bazı kanser türlerinin riskinin azaltılmasında ve kolon sağlı̆ı üzerinde olumlu etkiler gösterebilmektedir (Wong vd., 2006). Sindirilmeden kalın bağırsağa ulaşan DN, AACC (2000) tarafindan verilen diyet lifi tanimina uymakta ve bir lif bileşeni olarak sınıflandırılmaktadır. DN'nin insan sağlığı üzerine etkilerinin araştırıldığ1 çalışmalarda; kolon kanserini önleyebildiği (Asp ve Bjorck, 1992), prebiyotik etkilerinin bulunduğu (Brown vd., 1996), tip 2 diyabet riskini düşürdügü (Meyer vd., 2000), safra taşı oluşumunu azaltabildiği (Birkett vd., 2000), postprandiyal lipit oksidasyonunu arturarak uzun dönemde yă birikimini önleyebildiği (Higgins vd., 2004), kalsiyum ve demir emilimini artırabildiği (Morais vd., 1996) bildirilmektedir.

Buğday ununda bulunan gluten proteininin mükemmel visko-elastik özellikleri; ortamdaki havanın ve maya faaliyeti sonucu oluşan karbondioksitin hamur içinde tutulmasına, böylece kabaran, hacimli ve gözenekli yapıda ekmek oluşumuna imkan vermektedir (Pomeranz, 1987; Dizlek vd., 2013). Buğday ununun lüpen unu ve DN ile ikamesi; gluten oranında seyrelmeye, hamurun visko-elastik özelliklerinde ve pişme performansında azalmaya sebep olarak, ekmeğin teknolojik kalitesinin düşmesine neden olabilmektedir (Dervas vd., 1999; Sanchez vd., 2014). Vital gluten, genellikle tahil ve baklagil unlar1 ilavesiyle bozulan teknolojik özelliklerin buğday ununa geri kazandırılmasını sağlamakta; hamur mukavemetini, yoğurma toleransını ve elle işleme özelliklerini geliştirmektedir (Day vd., 2006).

Bir emülgatör olan sodyum stearol-2-laktilat (SSL); hamur yoğurma esnasinda gluten ile etkileşime girerek hamur mukavemetinin artmasinı, bayatlamanin gecikmesini ve yapışkanlı̆̆ın azalmasını sağlamaktadır (van Steertegem vd., 2013). Gomes-Ruffi vd. (2012), ekmek yapımında SSL kullanımı ile ekmek içinin yumuşadığını, gözenek yapısının iyileştiğini, ekmek hacminin arttığını ve daha uzun raf ömrüne sahip ekmek elde ettiklerini raporlamışardır.

$\mathrm{Bu}$ çalışmada; buğday unu, farklı metotlarla (geleneksel ve ultrason uygulamalı) acilı̆̆1 giderilmiş lüpen unu $(\% 10)$ ve DN (\%10) ile ikame edilerek ekmek üretimi gerçekleştirilmiştir. Lüpen unu ve DN ilavesiyle bozulan ekmek kalitesinin iyileştirilmesi için çeşitli katkı maddeleri (vital gluten, SSL ya da vital gluten+SSL) kullanılarak kalite üzerine etkilerinin belirlenmesi amaçlanmıştır. 


\section{MATERYAL VE YÖNTEM \\ Materyal}

Buğday unu (\%0.62 kül ve $\% 11.34$ protein; Hekimoğlu, Konya, Türkiye), yaş maya (Pakmaya, Kocaeli, Türkiye), tuz ve DN (tip4) Konya (Türkiye) piyasasından tedarik edilmiştir. Vital gluten ve SSL Vatan Enzim A.Ş.'den (İstanbul, Türkiye) alınmıştır.

$\mathrm{Bu}$ çalışmada kullanılan lüpen unları (geleneksel yöntemle acilı̆̆1 giderilmiş lüpen unu (GALU)/ultrason uygulamasiyla acilığ1 giderilmiş lüpen unu (UALU)), 1190071 no'lu proje ile TÜBITTAK tarafindan desteklenen daha önceki çalışmamızda elde edilmiştir. Bu amaçla, acı lüpen tohumları geleneksel yöntem (144 saat) ve ultrason uygulamalı yöntem $\left(25^{\circ} \mathrm{C}\right.$ - her 4 saatte bir $25 \mathrm{dk}$ ultrasonikasyon - toplam 60 saat) olmak üzere iki farklı metot kullanılarak acılık giderme işlemine tabi tutulmuştur. Her iki acılık giderme yönteminde de lüpen tohumlarına 1:3 (lüpen:su, w/v) oranında saf su eklenmiş ve $75 \mathrm{dk}$ süre ile 1 sıl işlem uygulanmıştır. Ardından örneklere 1:10 (lüpen:su, w/v) oranında saf su eklenmiş; geleneksel yöntemde her 4 saatte bir su değiştirilerek, 144 saat boyunca örnekler sslatma işlemine tabi tutulmuş, ultrason uygulamalı yöntemde ise 60 saat boyunca her 4 saatte bir örneklerin ıslatma suyu $\left(25^{\circ} \mathrm{C}\right)$ değiştirilmiş ve 25 $\mathrm{dk}$ süre ile ultrason uygulanmıştır. Acıllğ 1 giderilmiş lüpen tohumları (toplam alkaloit miktarı $<0.02 \mathrm{~g} / 100 \mathrm{~g})$ ögütülerek un haline getirilmiş, daha sonra kuru kavurma yöntemi (160 ${ }^{\circ} \mathrm{C}$ - $30 \mathrm{dk}$ ) ile stabilize edilmiştir (Yaver, 2021).

\section{Yöntem}

\section{Ekmek Üretimi}

Kontrol-1 \%100 buğday unu ekmeği üretimi için; $100 \mathrm{~g}$ un esasına göre $3 \mathrm{~g}$ yaş maya, $1.5 \mathrm{~g}$ tuz ve su, mikser (Hobart N50, Offenburg, Almanya) içerisinde karıştırıldıktan sonra düşük hızda $5 \mathrm{dk}$ ve yüksek hızda $2 \mathrm{dk}$ süre ile homojen bir hamur elde edilene kadar yoğrulmuştur. Elde edilen hamurlar, $30{ }^{\circ} \mathrm{C}$ 'de ve $\% 80-90$ nispi nemde kitle fermentasyonuna $(30+30 \mathrm{dk})$ bırakılmış, $30 \mathrm{dk}$ 'da bir katlanarak havalandirlmıs, daha sonra şekillendirilerek $60 \mathrm{dk}$ dinlendirilmiştir. Fermentasyon süresi sonunda hamurlar, 230
${ }^{\circ}$ C'deki firında (Fimak Rokon Classic FRN10 G, Konya, Türkiye) $9 \mathrm{dk}$ süreyle pişirilmiştir.

Kontrol-2 ekmek örneğinin üretiminde; buğday unu \%10 lüpen unu (GALU/UALU) + \%10 DN ile ikame edilmiş, Kontrol-1 ekmeğinin üretiminde uygulanan prosedür aynı şekilde uygulanmıştır. Lüpen unu ve DN kullanım oranı, önceki çalışmamızda farklı lüpen unu $(\% 0,10,15$ ve 20$)$ ve $\mathrm{DN}(\% 0,5$ ve 10$)$ ikame oranları arasında teknolojik kalite açısından en ümitvar bulunan örneğin \%10 lüpen unu $+\% 10$ DN kullanılarak üretilen ekmek örneği olması ile belirlenmiş ve katkı maddelerinin ilave edilmesi üzerine yapilan denemeler bu ekmek formülasyonu (Kontrol-2) üzerinde gerçekleştirilmiştir (Yaver, 2021). Katkı maddeleri ilave edilmiş ekmek denemeleri için; Kontrol-2 ekmek formülasyonuna (\%10 lüpen unu $+\% 10$ DN) seyrelen miktarda vital gluten, \%0.5 SSL ve aynı oranlarda vital gluten:SSL kombinasyonu ilave edilmiş ve yukarıda bahsedilen ekmek üretim prosedürünün aynısı uygulanmıştır.

\section{Renk Ölçümü}

Ekmek örneklerine ait renk değerleri $\left(L^{*}, a^{*}\right.$ ve $\left.b^{*}\right)$ Minolta CR-400 (Konica Minolta, Inc., Osaka, Japonya) cihazı kullanılarak Francis (1998)'e göre belirlenmiştir. Renk değerleri, hem ekmek kabuğu hem de ekmek içinde beş farklı noktadan ölçüm yapılması ile bulunmuştur.

\section{Ağırlık, Hacim ve Spesifik Hacim}

Ağırllk ve hacim değerleri, ekmek örneklerinin firından çıkmasını takiben $60 \mathrm{dk}$ sonra ölçülmüştür. Hacim ölçümü kolza tohumu ile yer değiştirme esasına göre, AACC 10-05 metoduna uygun olarak yapılmıştır (AACC, 1990). Ekmek örneklerine ait hacim değerinin ağırlık değerine oranlanması ile spesifik hacim değeri bulunmuştur (Elgün vd., 2001).

\section{Tekstür Analizleri}

Ekmek örneklerine ait 1. ve 3. günlerde ölçülen s1k1lik, sertlik, elastikiyet, koheziflik, çiğnenebilirlik ve esneklik değerleri tekstür analiz cihaz1 (Stable Microsystems TA-XT.Plus, Surrey, Birleşik Krallık) kullanılarak ve AACC 74-09 metoduna uygun olarak belirlenmiştir (AACC, 2000). 


\section{Duyusal Analizler}

Duyusal analizler 12 panelist tarafindan, ekmek örneklerinin tat, koku, görünüş, simetri, gözenek yapıs1 ve genel beğeni özelliklerinin değerlendirilmesi ile gerçekleștirilmiştir. Değerlendirme, 1-9 arasındaki skala (1: aşırı kötü, 5: orta, 9: aşırı iyi) kullanılarak yapılmıştır (Hooda ve Jood, 2005).

\section{İstatistiksel Analiz}

İstatistiki analizlerde TARIST 4.01 (Ege Üniversitesi, İzmir, Türkiye) programı kullanılarak sonuçlara varyans analizi (ANOVA) uygulanmış, ana varyasyon kaynaklarının ortalamaları arasındaki farklar Duncan çoklu karşılaştırma testi ile belirlenmiştir $(P<0.05)$. Analiz sonuçları ortalama土standart sapma şeklinde verilmiştir (Düzgüneş vd., 1987).

\section{SONUÇ VE TARTIŞMA}

Ekmek örneklerine ait kabuk $L^{*}, a^{*}$ ve $b^{*}$ değerleri Çizelge 1'de gösterilmiştir. Ekmeklerin üretiminde kullanılan lüpen ununun çeşidi (GALU ve UALU), örneklerin ortalama kabuk $L^{*}, a^{*}$ ve $b^{*}$ değerleri üzerinde istatistiki açıdan bir farklılık oluşturmamıştır $(P>0.05)$. Sonuçlar katkı çeşidi faktörü açısından değerlendirildiğinde; Kontrol-2 (\%10 lüpen unu + \%10 DN) örneğinin kabuk $L^{*}$ değerinin, Kontrol-1 (\%100 buğday unu) örneğine göre daha yüksek olduğu bulunmuştur. Kontrol-2 ekmeği formülasyonuna ilave edilen katk1 maddelerine (vital gluten, SSL ve vital gluten+SSL) ait kabuk $L^{*}$ değerinin, Kontrol-2 ekmeğine istatistiki açıdan benzer olduğu belirlenmiştir $(P>0.05)$. En yüksek ortalama kabuk $a^{*}$ değeri (10.61) Kontrol-1 örneğinde bulunurken, en düşük ortalama kabuk $a^{*}$ değeri Kontrol-2 (7.23) ekmeği ile "\%10 lüpen unu + \%10 DN + SSL" katkılı ekmek örneğinde (7.15) elde edilmiştir. Ekmek formülasyonuna beyaz renkli DN ilavesinin, \%10 lüpen unu + \%10 DN içeren ekmek örneklerinin Kontrol-1 ekmeğine göre daha yüksek $L^{*}$ ve daha düşük $a^{*}$ değerlerine sahip olmasında etkili olduğu tahmin edilmektedir. Ekmek örneklerinin ortalama kabuk $b^{*}$ değeri üzerinde katkı çeşidinin önemli ( $P$ $>0.05)$ bir etkisinin bulunmadığ görülmüsstür. Benzer sonuçlar Yıldız (2009) tarafindan da elde edilmiş, "\%20 karabuğday unu + vital gluten + SSL" içeren ekmeğin kabuk $L^{*}$ ve $b^{*}$ değerlerinin katkısız ekmeğe yakın olduğu bildirilmiştir.

Çizelge 1. Ekmek örneklerine ait kabuk renk değerleri1

Table 1. Crust color values of bread samples ${ }^{1}$

\begin{tabular}{lcccc}
\hline $\begin{array}{l}\text { Faktör/ } \\
\text { Factor }\end{array}$ & $\mathrm{n}$ & $L^{*}$ & $a^{*}$ & $b^{*}$ \\
\hline $\begin{array}{l}\text { Lüpen unu cessidil } \\
\text { Lupin flour type }\end{array}$ & & & & \\
GALU $^{2}$ & 10 & $61.45 \pm 1.96^{\mathrm{a}}$ & $8.34 \pm 1.41^{\mathrm{a}}$ & $32.01 \pm 0.49^{\mathrm{a}}$ \\
UALU $^{3}$ & 10 & $61.38 \pm 1.86^{\mathrm{a}}$ & $8.29 \pm 1.45^{\mathrm{a}}$ & $31.94 \pm 0.34^{\mathrm{a}}$ \\
\hline Katke cessidi/ $^{\text {Additives }}$ & & & & \\
Kontrol-14/ Control-14 & 4 & $58.16 \pm 0.13^{\mathrm{b}}$ & $10.61 \pm 0.06^{\mathrm{a}}$ & $31.78 \pm 0.10^{\mathrm{a}}$ \\
Kontrol-25/ Control-2 & 4 & $62.45 \pm 0.53^{\mathrm{a}}$ & $7.23 \pm 0.25^{\mathrm{d}}$ & $32.41 \pm 0.39^{\mathrm{a}}$ \\
VG $^{6}$ & 4 & $61.31 \pm 0.18^{\mathrm{a}}$ & $8.70 \pm 0.10^{\mathrm{b}}$ & $32.32 \pm 0.10^{\mathrm{a}}$ \\
SSL $^{7}$ & 4 & $62.60 \pm 0.11^{\mathrm{a}}$ & $7.15 \pm 0.00^{\mathrm{d}}$ & $31.66 \pm 0.39^{\mathrm{a}}$ \\
VG+SSL & 4 & $62.54 \pm 0.25^{\mathrm{a}}$ & $7.87 \pm 0.03^{\mathrm{c}}$ & $31.69 \pm 0.23^{\mathrm{a}}$ \\
\hline
\end{tabular}

${ }^{1}$ Sonuçlar iki tekerrürün ortalamasıdır. Farklı harfle işaretlenmiş, aynı sütundaki ortalamalar istatistiki olarak birbirinden farklidır $(P<0.05) . /{ }^{1}$ Values are the average of duplicate samples. Means followed by the different letter within a column are statistically different from each other $(P<0.05)$.

${ }^{2}$ Geleneksel yöntemle acilığı giderilmiş lüpen unu. $/{ }^{2}$ Lupin flour debittered by traditional method.

${ }^{3}$ Ultrason uygulamasıyla acılloğ giderilmiş lüpen unu. $/{ }^{3}$ Lupin flour debittered by ultrasound application.

$4 \% 100$ buğday unu. $/{ }^{4} 100 \%$ wheat flour.

5\%10 lüpen unu $+\% 10$ dirençli nişasta. $/ 510 \%$ lupin flour $+10 \%$ resistant starch.

${ }^{6}$ Vital gluten.

${ }^{7}$ Sodyum stearol-2-laktilat./7 Sodium stearoyl-2-lactylate. 
Ekmek örneklerine ait iç $L^{*}, a^{*}$ ve $b^{*}$ değerleri Çizelge 2'de verilmiştir. GALU ve UALU kullanılarak üretilen ekmeklerin ortalama iç $L^{*}, a^{*}$ ve $b^{*}$ değerlerinin birbirine yakın olduğu, aralarında anlamlı bir fark oluşmadığı belirlenmiştir $(P$ >0.05). Katkısız Kontrol-2 örneği ile katkı maddeleri ilave edilerek üretilen ekmek örneklerine ait ortalama iç $L^{*}$ değerleri birbirine yakın $(P>0.05)$ ve Kontrol-1 ekmeğinin ortalama iç $L^{*}$ değerine göre daha düşük bulunmuştur. Katk1 maddelerinin ilavesi, Kontrol-2 ekmeğinin ortalama iç $a^{*}$ değerini sayısal olarak azaltmış, ancak bu farkın istatistiki açıdan önemsiz $(P>0.05)$ olduğu görülmüştür. Kontrol-2 ekmeğinde, Kontrol-1 ekmeğine göre daha yüksek ortalama iç $b^{*}$ değeri elde edilmiştir. Kontrol-2 formülasyonunda yer alan lüpen ununun bileşiminde bulunan pigmentler, muhtemelen bu artış üzerinde etkili olmuştur. Vital gluten ve vital gluten+SSL katkılanı, katkısız Kontrol-2 ekmeğinin ortalama iç $b^{*}$ değerini azaltmıştır. Kim vd. (2013); vital gluten katkısının, ekmek örneklerine ait iç $a^{*}$ değerinin katkısız kontrol örneğine yakın olmasını sağladığını, iç $b^{*}$ değerini ise azalttı̆̆ını ifade etmişlerdir.

Çizelge 2. Ekmek örneklerine ait ekmek içi renk değerleri1 ${ }^{1}$

Table 2. Crumb color values of bread samples ${ }^{1}$

\begin{tabular}{lcccc}
\hline $\begin{array}{l}\text { Faktör/ } \\
\text { Factor }\end{array}$ & $\mathrm{n}$ & $L^{*}$ & $a^{*}$ & $b^{*}$ \\
\hline $\begin{array}{l}\text { Lüpen unu çesidil } \\
\text { Lupin flour type }\end{array}$ & & & & \\
GALU $^{2}$ & 10 & $70.45 \pm 1.26^{\mathrm{a}}$ & $-1.78 \pm 0.15^{\mathrm{a}}$ & $20.81 \pm 3.48^{\mathrm{a}}$ \\
UALU $^{3}$ & 10 & $70.35 \pm 1.35^{\mathrm{a}}$ & $-1.77 \pm 0.21^{\mathrm{a}}$ & $20.78 \pm 3.52^{\mathrm{a}}$ \\
\hline Katkr çesidi/ $^{\text {Additives }}$ & & & & \\
Kontrol-14/ Control-14 & 4 & $72.61 \pm 0.02^{\mathrm{a}}$ & $-1.55 \pm 0.05^{\mathrm{a}}$ & $14.67 \pm 0.11^{\mathrm{c}}$ \\
Kontrol-25/ Control-25 $^{5}$ & 4 & $70.53 \pm 0.06^{\mathrm{b}}$ & $-1.61 \pm 0.06^{\mathrm{a}}$ & $23.21 \pm 0.10^{\mathrm{a}}$ \\
VG $^{6}$ & 4 & $69.53 \pm 0.32^{\mathrm{b}}$ & $-1.85 \pm 0.03^{\mathrm{a}}$ & $21.66 \pm 0.21^{\mathrm{b}}$ \\
SSL7 & 4 & $69.60 \pm 0.07 \mathrm{~b}$ & $-1.93 \pm 0.02^{\mathrm{a}}$ & $22.87 \pm 0.01^{\mathrm{ab}}$ \\
VG+SSL & 4 & $69.72 \pm 0.08^{\mathrm{b}}$ & $-1.92 \pm 0.01^{\mathrm{a}}$ & $21.58 \pm 0.10^{\mathrm{b}}$ \\
\hline
\end{tabular}

${ }^{1}$ Sonuçlar iki tekerrürün ortalamasıdır. Farklı harfle işaretlenmiş, aynı sütundaki ortalamalar istatistiki olarak birbirinden farklidir $(P<0.05) . /{ }^{1} V$ alues are the average of duplicate samples. Means followed by the different letter within a column are statistically different from each other $(P<0.05)$.

${ }^{2}$ Geleneksel yöntemle acllığı giderilmiş lüpen unu. $/{ }^{2}$ Lupin flour debittered by traditional method.

${ }^{3}$ Ultrason uygulamasıyla acıllŏı giderilmiş lüpen unu./ ${ }^{3}$ Lupin flour debittered by ultrasound application.

$4 \% 100$ buğday unu. $/{ }^{4} 100 \%$ wheat flour.

5\%10 lüpen unu $+\% 10$ dirençli nişasta. $/ 510 \%$ lupin flour $+10 \%$ resistant starch.

${ }^{\circ}$ Vital gluten.

${ }^{7}$ Sodyum stearol-2-laktilat./'Sodium stearoyl-2-lactylate.

Ekmek örneklerine ait ağırlık, hacim ve spesifik hacim sonuçları Çizelge 3'te verilmiştir. Ekmek örneklerinin üretiminde lüpen unu çeşidi olarak UALU kullanımı, GALU kullanılarak üretilen ekmeklere göre daha düşük ağırlık değerleri ile daha yüksek hacim ve spesifik hacim değerleri sağlamıştr. UALU örneklerinin elde edilmesinde kullanılan ultrason uygulamasinın oksidasyona ve bunun sonucunda da hidroperoksitlerin oluşumuna neden olduğu bilinmektedir (Jiang vd., 2014). UALU örneklerinde bulunan hidroperoksitler, UALU içeren ekmeklerde hamur oksidasyonu ile serbest sülfidril (-SH) gruplarının disülfit (S-S) gruplarına dönüşümünü sağlayarak gluten ağını güçlendirmiş ve ekmek hacminin artmasını sağlamış olabilir (Yang vd., 2018; Li vd., 2019). Katk1 çeşidi faktörü açısından yapılan değerlendirmede; katkısız Kontrol-2 ekmeğinin ortalama ağırlık değeri 155.32 g olarak bulunmuş; vital gluten, SSL ve vital gluten+SSL ilavesi ile ekmek örneklerinin ortalama ağırlık değerlerinin sırasıly $151.22 \mathrm{~g}, 153.31 \mathrm{~g}$ ve 148.62 
g’a düştüğü görülmüştür. \%10 lüpen unu $+\% 10$ DN formülasyonuna ilave edilen katk1 maddelerinin üçü de (vital gluten, SSL ve vital gluten+SSL) hacim ve spesifik hacim değerlerinin katkısız Kontrol-2 ekmek örneğine göre artmasını sağlamıs, istatistiki açıdan en yüksek hacim ve spesifik hacim değerleri ise Kontrol-1 örneğinde bulunmuştur $(P<0.05)$. Şekil 1a'da gösterildiği gibi, hem GALU hem de UALU ilave edilerek üretilen ekmekler arasında Kontrol-1 örneğine en yakın hacim değeri vital gluten+SSL katkısı ile elde edilmiştir. Vital glutenin; hamur elastikiyetini, mukavemetini ve gaz tutma kapasitesini artıran visko-elastik özellikleri ve lüpen unu+DN ilavesi ile seyrelen gluten miktarını tamamlayıcı olması, hacim artısı üzerinde etkili olmaktadır (Dizlek vd., 2013; Ortolan ve Steel, 2017). SSL ise; gluten ve nişasta arasındaki arayüzde sıvı filmler oluşturarak gaz tutma kapasitesinin artmasını sağlamakta, bu da hacim ve spesifik hacim değerleri üzerinde olumlu etki oluşturmaktadır (Krog, 1981; GomesRuffi vd., 2012). Özkaya ve Özkaya (1992); \%20 oranında mısır unu içeren ekmek formülasyonuna vital gluten+SSL katkıs1 ilavesinin, ekmek örneklerinin hacim ve spesifik hacim değerlerini iyileştirdiğini raporlamışlardır.

Çizelge 3. Ekmek örneklerine ait ağırlık, hacim ve spesifik hacim değerleri ${ }^{1}$

Table 3. Weight, volume and specific volume values of bread samples ${ }^{1}$

\begin{tabular}{|c|c|c|c|c|}
\hline $\begin{array}{l}\text { Faktör/ } \\
\text { Factor }\end{array}$ & $\mathrm{n}$ & $\begin{array}{l}\text { Ağırlık (g)/ } \\
\text { Weight (g) }\end{array}$ & $\begin{array}{l}\text { Hacim }(\mathrm{ml}) / \\
\text { Volume }(\mathrm{ml})\end{array}$ & $\begin{array}{l}\text { Spesifik hacim }(\mathrm{ml} / \mathrm{g}) / \\
\text { Specific volume }(\mathrm{ml} / \mathrm{g})\end{array}$ \\
\hline \multicolumn{5}{|l|}{ Lüpen unu çeşidil } \\
\hline \multicolumn{5}{|l|}{ Lupin flour type } \\
\hline GALU $22^{2}$ & 10 & $152.24 \pm 4.29 a$ & $517.39 \pm 82.61^{b}$ & $3.41 \pm 0.64 \mathrm{~b}$ \\
\hline UALU $^{3}$ & 10 & $149.60 \pm 3.12^{\mathrm{b}}$ & $551.79 \pm 62.59^{a}$ & $3.70 \pm 0.49 \mathrm{a}$ \\
\hline \multicolumn{5}{|l|}{ Katke çessidil } \\
\hline Kontrol-14/ Control-14 & 4 & $146.10 \pm 0.67 \mathrm{e}$ & $626.93 \pm 2.20^{\mathrm{a}}$ & $4.29 \pm 0.03^{a}$ \\
\hline Kontrol-25/ Control-25 & 4 & $155.32 \pm 3.73^{a}$ & $432.48 \pm 50.01^{\mathrm{e}}$ & $2.79 \pm 0.39 \mathrm{~d}$ \\
\hline $\mathrm{VG}^{6}$ & 4 & $151.22 \pm 1.39 c$ & $543.19 \pm 25.41^{c}$ & $3.59 \pm 0.20^{b c}$ \\
\hline $\mathrm{SSL}^{7}$ & 4 & $153.31 \pm 1.46^{b}$ & $505.25 \pm 12.83^{d}$ & $3.29 \pm 0.12^{c}$ \\
\hline $\mathrm{VG}+\mathrm{SSL}$ & 4 & $148.62 \pm 2.08^{d}$ & $565.11 \pm 31.16^{\mathrm{b}}$ & $3.81 \pm 0.26^{\mathrm{b}}$ \\
\hline
\end{tabular}

${ }^{1}$ Sonuçlar iki tekerrürün ortalamasıdır. Farklı harfle işaretlenmiş, aynı sütundaki ortalamalar istatistiki olarak birbirinden farklidir $(P<0.05) . /{ }^{1} V$ alues are the average of duplicate samples. Means followed by the different letter within a column are statistically different from each other $(P<0.05)$.

${ }^{2}$ Geleneksel yöntemle acillğ̣ giderilmiş lüpen unu. $/{ }^{2}$ Lupin flour debittered by traditional method.

${ }^{3}$ Ultrason uygulamasıyla acıllŏı giderilmiş lüpen unu./ ${ }^{3}$ Lupin flour debittered by ultrasound application.

$4 \% 100$ buğday unu. $/{ }^{4} 100 \%$ wheat flour.

5\%10 lüpen unu $+\% 10$ dirençli nişasta. $/ 510 \%$ lupin flour $+10 \%$ resistant starch.

${ }^{6}$ Vital gluten.

${ }^{7}$ Sodyum stearol-2-laktilat./' Sodium stearoyl-2-lactylate.

Ekmek örneklerine ait 1. gün tekstür analiz sonuçları Çizelge 4'te verilmiştir. Ortalama 1. gün sıkılık, sertlik ve çiğnenebilirlik değerleri; GALU kullanılarak üretilen ekmek örneklerinde sirasıyla $474 \mathrm{~g}, 712 \mathrm{~g}$ ve $401 \mathrm{~g}$, UALU ile hazırlanan örneklerde ise sirasiyla 376 g, $626 \mathrm{~g}$ ve $371 \mathrm{~g}$ olarak bulunmuştur. Ekmek hacmindeki artışin sikilık, sertlik ve çiğnenebilirlik değerleri üzerinde olumlu etki gösterdiği belirtilmektedir (Güdük, 2016). UALU içeren ekmeklerin GALU içeren ekmeklere göre daha yüksek hacim değerlerine sahip olmasının tekstürel özelliklere de yansıdığ1 düşünülmektedir (Çizelge 3 ve 4). Lüpen unu çeşidinin, ekmeklerin 1. gün elastikiyet, koheziflik ve esneklik değerleri üzerinde önemli $(P>0.05)$ bir etki oluşturmadığ1 belirlenmiştir. Kontrol-1 örneği ile karşılaştırıldığında, ekmek üretiminde $\% 10$ lüpen unu $+\% 10 \mathrm{DN}$ kullanımının (Kontrol-2) ortalama 1. gün sikılik, sertlik ve çiğnenebilirlik değerlerinin artmasına neden olduğu görülmüştür. Lüpen unu ve DN ilavesi ile gluten miktarnnda meydana gelen seyrelmenin gaz 
tutma kapasitesinin azalmasina neden olmasi, gözenek yapısı gelişimini olumsuz etkilemekte; sıkılık, sertlik ve çiğnenebilirlik değerlerinin artış1 ile sonuçlanabilmektedir (Coda vd., 2017; Liu vd., 2017). Villarino vd. (2015); \%20 oranında lüpen unu kullanımının, ekmek örneklerinin sertlik ve çiğnenebilirlik değerlerini kontrol buğday unu ekmeğine göre artırdığını raporlamışlardır. SanzPenella vd. (2010) ise; \%10 oranında DN içeren ekmeklerin, buğday unu ekmeğine göre daha yüksek sertlik ve çiğnenebilirlik değerlerine sahip olduğunu ifade etmişlerdir. Kontrol-2 formülasyonuna ilave edilen katk1 maddelerinin üçü de Kontrol-2 ekmeğinin ortalama 1. gün sıkılık değerini azaltmış, en etkili sonuç vital gluten+SSL kombinasyonunun kullanımı ile elde edilmiştir (Şekil 1b). Vital gluten+SSL katkısı aynı zamanda; ortalama 1. gün sertlik değerinin Kontrol-1 ekmeğine yakın olmasını sağlamıs $(P$ $>0.05$ ), ortalama 1. gün çiğnenebilirlik değerini ise Kontrol-1'e göre düşürmüştür $(P<0.05)$. Curti vd. (2014), vital gluten ilavesinin gluten ağ1 gelişimini iyileştirerek gaz tutma kapasitesini artırması ile ekmek içi tekstürel özelliklerinin gelişimini desteklediğini raporlamışlardır. Ekmek üretiminde SSL kullanılan çalışmalarda ise, SSL'in daha yumuşak bir ekmek içi sağladığı ve gözenek yapısı gelişimini iyileştirerek ekmek içi tekstürü üzerinde olumlu sonuçlar verdiği belirtilmektedir (Sluimer, 2005; Khaleel vd., 2018). Katk1 çeşidi faktörü açısından; ekmek örneklerinin 1. gün elastikiyet, koheziflik ve esneklik değerleri arasında istatistiki açıdan bir farklılık oluşmadığı gözlenmiştir $(P>0.05)$.

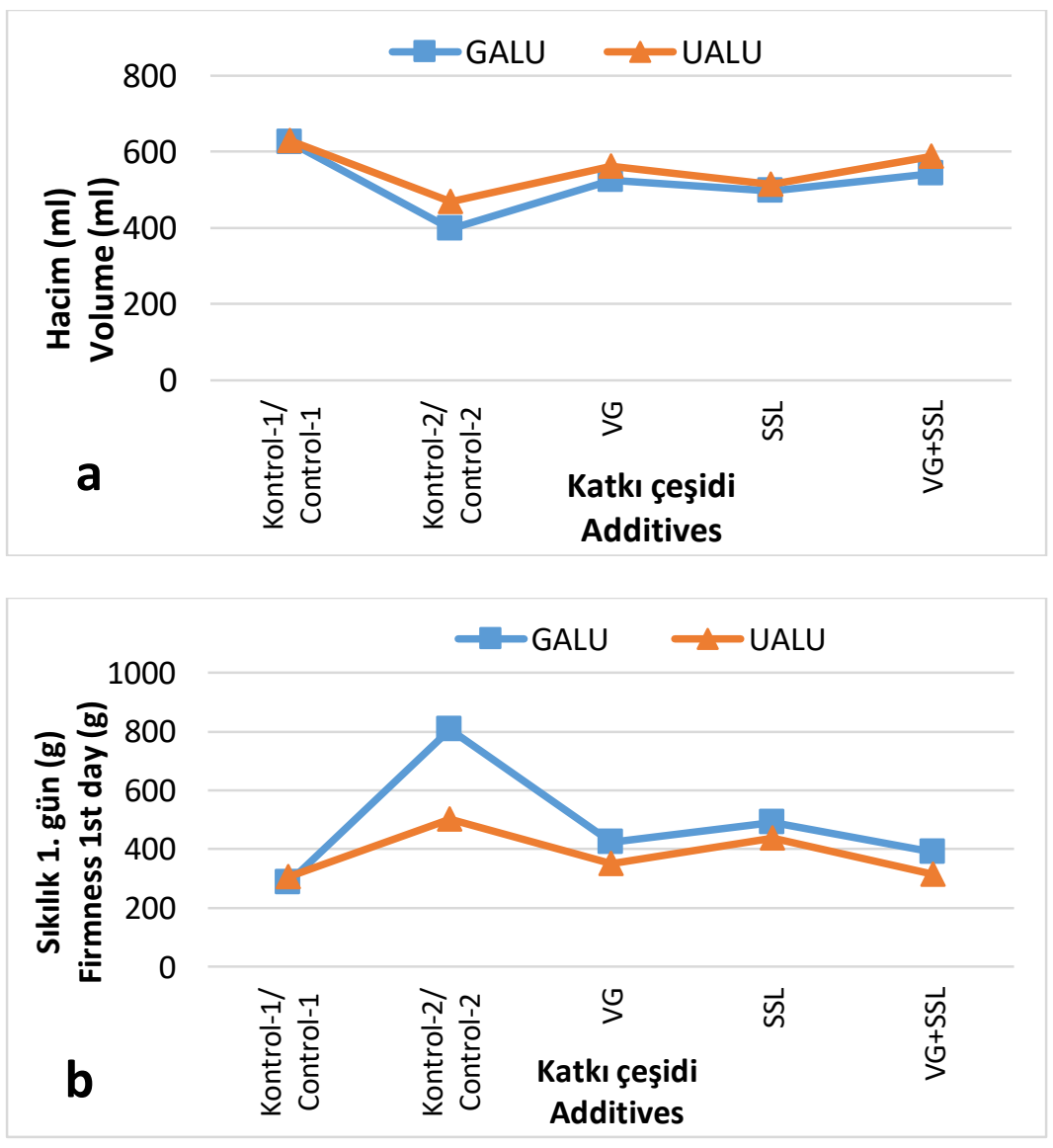

Şekil 1. Ekmek örneklerine ait hacim (a) ve 1. gün sik1lı (b) değerleri Figure 1. Volume (a) and 1 st day firmness (b) values of bread samples 
Çizelge 4. Ekmek örneklerine ait 1. gün tekstür analiz değerleri ${ }^{1}$ Table 4 . The $1^{\text {st }}$ day texture analysis values of bread samples

\begin{tabular}{|c|c|c|c|c|c|c|c|}
\hline $\begin{array}{l}\text { Faktör/ } \\
\text { Factor }\end{array}$ & $\mathrm{n}$ & $\begin{array}{l}\text { Sikilik }(\mathrm{g}) / \\
\text { Firmness }(g)\end{array}$ & $\begin{array}{l}\text { Sertlik }(\mathrm{g}) / \\
\text { Hardness (g) }\end{array}$ & $\begin{array}{c}\text { Elastikiyet/ } \\
\text { Springiness }\end{array}$ & $\begin{array}{l}\text { Koheziflik/ } \\
\text { Cohesiveness }\end{array}$ & $\begin{array}{l}\text { Çiğnenebilirlik }(\mathrm{g}) / \\
\text { Chewrness }(\mathrm{g})\end{array}$ & $\begin{array}{c}\text { Esneklik/ } \\
\text { Resilience }\end{array}$ \\
\hline $\begin{array}{l}\text { Lüpen unu çeşidi) } \\
\text { Lupin flour type }\end{array}$ & & & & & & & \\
\hline GALU2 & 10 & $474 \pm 197.41^{a}$ & $712 \pm 254.62^{\mathrm{a}}$ & $0.877 \pm 0.04 a$ & $0.664 \pm 0.06^{a}$ & $401 \pm 81.81^{\mathrm{a}}$ & $0.304 \pm 0.05^{\mathrm{a}}$ \\
\hline UALU3 $^{3}$ & 10 & $376 \pm 84.15^{b}$ & $626 \pm 155.89 \mathrm{~b}$ & $0.885 \pm 0.03^{a}$ & $0.681 \pm 0.04 \mathrm{a}$ & $67 \mathrm{~b}$ & $0.328 \pm 0.04 \mathrm{a}$ \\
\hline $\begin{array}{l}\text { Katker cesidil } \\
\text { Additives }\end{array}$ & & & & & & & \\
\hline $\begin{array}{l}\text { Kontrol-14 / } \\
\text { Control-14 }\end{array}$ & 4 & $296 \pm 13.44 \mathrm{e}$ & $530 \pm 5.66^{d}$ & $0.928 \pm 0.01^{a}$ & $0.728 \pm 0.01^{a}$ & $356 \pm 4.24 c$ & $0.356 \pm 0.00^{\mathrm{a}}$ \\
\hline $\begin{array}{l}\text { Kontrol-25/ } \\
\text { Control-25 }\end{array}$ & 4 & $655 \pm 217.08^{a}$ & $1021 \pm 185.26^{a}$ & $0.831 \pm 0.01^{\mathrm{a}}$ & $0.598 \pm 0.04 a$ & $503 \pm 53.74 a$ & $0.245 \pm 0.03^{\mathrm{a}}$ \\
\hline $\mathrm{VG}^{6}$ & 4 & $389 \pm 51.62^{c}$ & $580 \pm 26.16^{c}$ & $0.880 \pm 0.00^{a}$ & $0.680 \pm 0.01^{a}$ & $347 \pm 10.05^{\mathrm{cd}}$ & $0.330 \pm 0.02^{\mathrm{a}}$ \\
\hline $\mathrm{SSL}^{7}$ & 4 & $464 \pm 36.77 \mathrm{~b}$ & $675 \pm 45.96^{b}$ & $0.872 \pm 0.00^{\mathrm{a}}$ & $0.658 \pm 0.00^{a}$ & $388 \pm 26.71^{b}$ & $0.312 \pm 0.01^{\mathrm{a}}$ \\
\hline VG+SSL & 4 & $354 \pm 53.03^{\mathrm{d}}$ & $540 \pm 38.89^{d}$ & $0.893 \pm 0.00^{\mathrm{a}}$ & $0.697 \pm 0.01^{\mathrm{a}}$ & $336 \pm 19.94 \mathrm{~d}$ & $0.336 \pm 0.02^{\mathrm{a}}$ \\
\hline
\end{tabular}

${ }^{1}$ Sonuçlar iki tekerrürün ortalamasıdır. Farklı harfle ișaretlenmiș, aynı sütundaki ortalamalar istatistiki olarak birbirinden farklidır $(P<0.05) . /{ }^{\prime} V$ alues are the average of duplicate samples. Means followed by the different letter within a column are statistically different from each other $(P<0.05)$.

${ }^{2}$ Geleneksel yöntemle ac1loğ1 giderilmiş lüpen unu. $/{ }^{2}$ Lupin flour debittered by traditional method.

${ }^{3}$ Ultrason uygulamasıyla acıllŏı giderilmiş lüpen unu./ ${ }^{3}$ Lupin flour debittered by ultrasound application.

4\%100 buğday unu. $/{ }^{4} 100 \%$ wheat flour.

5010 lüpen unu $+\% 10$ dirençli nișasta. $/ 510 \%$ lupin flour $+10 \%$ resistant starch.

${ }^{6}$ Vital gluten.

${ }^{7}$ Sodyum stearol-2-laktilat./' ${ }^{7}$ Sodium stearoyl-2-lactylate.

Ekmek örneklerine ait 3. gün tekstür analiz değerleri Çizelge 5'te gösterilmiştir. Ekmek üretiminde UALU kullanımı, GALU içeren ekmeklere göre daha düşük ortalama 3. gün sık1lık ve sertlik değerleri sağlamıştır. Ekmeğin bayatlaması, depolama boyunca ekmek içinde kabuğa su transferi ve nişastanın yeniden kristalleşmesi ile gerçekleşmektedir (Martin vd., 1991). Lüpen unu çeşidi olarak UALU kullanımının, bayatlama üzerinde daha fazla avantaj sağladığı görülmektedir. Bunun yanında, GALU ve UALU ilave edilerek üretilen ekmek örneklerinin ortalama 3. gün elastikiyet, koheziflik, çiğnenebilirlik ve esneklik değerleri istatistiki açıdan birbirine benzer bulunmuştur ( $P$ $>0.05)$. Katk1 çeşidi faktörüne göre yapılan karşılaştırmada; en yüksek ortalama 3. gün sıkılık, sertlik ve çiğnenebilirlik değerleri katkısız Kontrol-2 ekmeğinde belirlenmiş, Kontrol-2 formülasyonuna (\%10 lüpen unu $+\% 10 \mathrm{DN})$ ilave edilen bütün katkı maddeleri, bu değerlerin katkısız Kontrol-2 ekmeğine göre düşmesine neden olmuştur. Katkı maddeleri kendi aralarında karşılaştırıldığında, en düşük ortalama 3. gün sıkılık ve sertlik değerleri vital gluten+SSL katkıs1 ile elde edilmiş, vital gluten ve vital gluten+SSL içeren ekmeklerin ortalama 3. gün çiğnenebilirlik değeri birbirine yakın bulunmuştur $(P>0.05)$. Willhoft (1973), vital gluten ilavesi ile ekmek hacminin artması ve nişasta miktarnnın seyrelmesi sonucu ekmek içi tekstürünün iyileștiğini bildirmiş; SSL'in bayatlama üzerindeki etkilerinin amilozla kompleks oluşturabilmesi, hamur kuvvetlendirici etki göstermesi ve su tutma kapasitesini artırmasından kaynaklandığını ifade etmiştir. Boz (2008), vital gluten ilavesinin ekmek örneklerinin 1. ve 3. gün sertlik değerinin katkısız örneğe göre daha düşük olmasını sağladığını raporlamıştır. Khaleel vd. (2018) tarafindan, SSL ilave edilerek üretilen ekmeklerin 0 . ve 4. gün sertlik ve çiğnenebilirlik değerlerinin katkısız ekmek örneklerine göre daha düşük olduğu bulunmuştur. Katkı11 (vital gluten, SSL ve vital gluten+SSL) ekmek örnekleri kendi aralarında değerlendirildiğinde, 3. gün elastikiyet, koheziflik ve esneklik değerlerinde istatistiki açıdan bir farklılık oluşmadığ1 görülmüştür $(P>0.05)$.

GALU (a) ve UALU (b) kullanılarak üretilen ekmek örneklerine ait duyusal analiz sonuçları Şekil 2'de gösterilmiştir. Hem GALU hem de UALU ilave edilerek üretilen ekmeklerin tat, koku 
ve simetri puanlarının birbirine yakın olduğu belirlenmiştir $(P>0.05)$. Vital gluten, SSL ve vital gluten+SSL içeren ekmeklerin görünüş ve gözenek yapısı puanları, Kontrol-1 ekmeğine yakın bulunmuştur. GALU ve UALU ihtiva eden örneklerde vital gluten ve vital gluten+SSL kullanımı, katkısız Kontrol-2 örneğinin genel beğeni puanının Kontrol-1 ekmeğine yakınlaşmasını sağlamışır. Kim vd. (2013), vital gluten katkilı ekmek örneğinin genel beğeni puanının katkısız ekmek örneğinden daha yüksek olduğunu bildirmişlerdir.

Çizelge 5. Ekmek örneklerine ait 3. gün tekstür analiz değerleri ${ }^{1}$

Table 5. The $3^{\text {rd }}$ day texture analysis values of bread samples ${ }^{1}$

\begin{tabular}{|c|c|c|c|c|c|c|c|}
\hline $\begin{array}{l}\text { Faktör/ } \\
\text { Factor }\end{array}$ & $\mathrm{n}$ & $\begin{array}{l}\text { Sik1lik }(\mathrm{g}) / \\
\text { Firmness (g) }\end{array}$ & $\begin{array}{l}\text { Sertlik }(\mathrm{g}) / \\
\text { Hardness }(\mathrm{g})\end{array}$ & $\begin{array}{l}\text { Elastikiyet/ } \\
\text { Springiness }\end{array}$ & $\begin{array}{l}\text { Koheziflik/ } \\
\text { Cobesiveness }\end{array}$ & $\begin{array}{l}\text { Çiğnenebilirlik(g)/ } \\
\text { Chewiness (g) }\end{array}$ & $\begin{array}{l}\text { Esneklik/ } \\
\text { Resilience }\end{array}$ \\
\hline \multicolumn{8}{|c|}{ Lüpen unu çessidil } \\
\hline \multicolumn{8}{|c|}{ Lupin flour type } \\
\hline GALU $^{2}$ & 10 & $748 \pm 254.56^{a}$ & $971 \pm 273.46^{a}$ & $0.852 \pm 0.04^{a}$ & $0.524 \pm 0.07^{\mathrm{a}}$ & $422 \pm 69.89^{a}$ & $0.203 \pm 0.04^{\mathrm{a}}$ \\
\hline UALU $^{3}$ & 10 & $598 \pm 164.52^{\mathrm{b}}$ & $915 \pm 226.09^{\mathrm{b}}$ & $0.857 \pm 0.04^{a}$ & $0.561 \pm 0.08^{\mathrm{a}}$ & $427 \pm 32.59^{a}$ & $0.225 \pm 0.03^{a}$ \\
\hline \multicolumn{8}{|l|}{$\begin{array}{l}\text { Katker çessidil } \\
\text { Additives }\end{array}$} \\
\hline $\begin{array}{l}\text { Kontrol-14/ } \\
\text { Control-14 }\end{array}$ & 4 & $435 \pm 5.66^{\mathrm{e}}$ & $783 \pm 6.36^{\mathrm{d}}$ & $0.924 \pm 0.00^{\mathrm{a}}$ & $0.627 \pm 0.00^{\mathrm{a}}$ & $455 \pm 3.54^{\mathrm{b}}$ & $0.264 \pm 0.00^{a}$ \\
\hline $\begin{array}{l}\text { Kontrol-25/ } \\
\text { Control-25 }\end{array}$ & 4 & $970 \pm 205.06^{a}$ & $1380 \pm 96.17^{a}$ & $0.823 \pm 0.01^{a}$ & $0.443 \pm 0.01^{\mathrm{b}}$ & $500 \pm 41.01^{a}$ & $0.173 \pm 0.03^{\mathrm{a}}$ \\
\hline $\mathrm{VG}^{6}$ & 4 & $650 \pm 94.75^{c}$ & $851 \pm 20.51^{\mathrm{c}}$ & $0.841 \pm 0.00^{\mathrm{a}}$ & $0.545 \pm 0.04^{\mathrm{ab}}$ & $390 \pm 21.59^{\mathrm{cd}}$ & $0.220 \pm 0.02^{\mathrm{a}}$ \\
\hline $\mathrm{SSL}^{7}$ & 4 & $769 \pm 108.19^{\mathrm{b}}$ & $910 \pm 50.91^{\mathrm{b}}$ & $0.835 \pm 0.00^{\mathrm{a}}$ & $0.521 \pm 0.05^{\mathrm{ab}}$ & $395 \pm 13.96^{c}$ & $0.187 \pm 0.00^{\mathrm{a}}$ \\
\hline $\mathrm{VG}+\mathrm{SSL}$ & 4 & $541 \pm 129.40^{\mathrm{d}}$ & $791 \pm 26.16^{\mathrm{d}}$ & $0.846 \pm 0.00^{a}$ & $0.574 \pm 0.05^{\mathrm{ab}}$ & $383 \pm 25.18^{\mathrm{d}}$ & $0.226 \pm 0.03^{\mathrm{a}}$ \\
\hline
\end{tabular}

${ }^{1}$ Sonuçlar iki tekerrürün ortalamasıdır. Farklı harfle işaretlenmiş, aynı sütundaki ortalamalar istatistiki olarak birbirinden farklidır $(P<0.05) . /{ }^{\prime} V$ alues are the average of duplicate samples. Means followed by the different letter within a column are statistically different from each other $(P<0.05)$.

${ }^{2}$ Geleneksel yöntemle acllğ̆1 giderilmiş lüpen unu. ${ }^{2}$ Lupin flour debittered by traditional method.

${ }^{3}$ Ultrason uygulamasıyla ac1lığ giderilmiş lüpen unu. $/{ }^{3}$ Lupin flour debittered by ultrasound application.

$4 \% 100$ buğday unu. $/{ }^{4} 100 \%$ wheat flour.

5\%10 lüpen unu $+\% 10$ dirençli nişasta. $/ 510 \%$ lupin flour $+10 \%$ resistant starch.

${ }^{\circ}$ Vital gluten.

${ }^{7}$ Sodyum stearol-2-laktilat./7 Sodium stearoyl-2-lactylate.

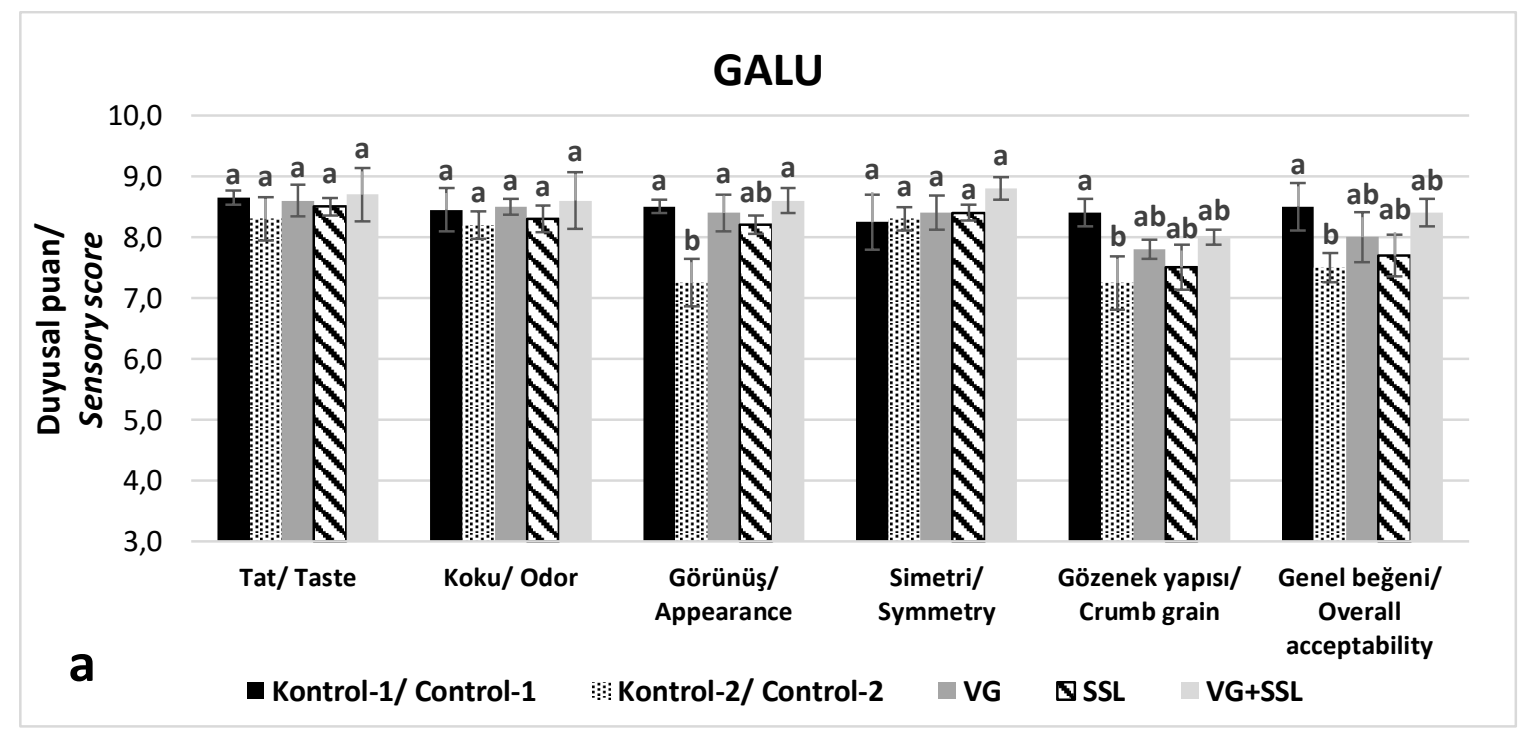




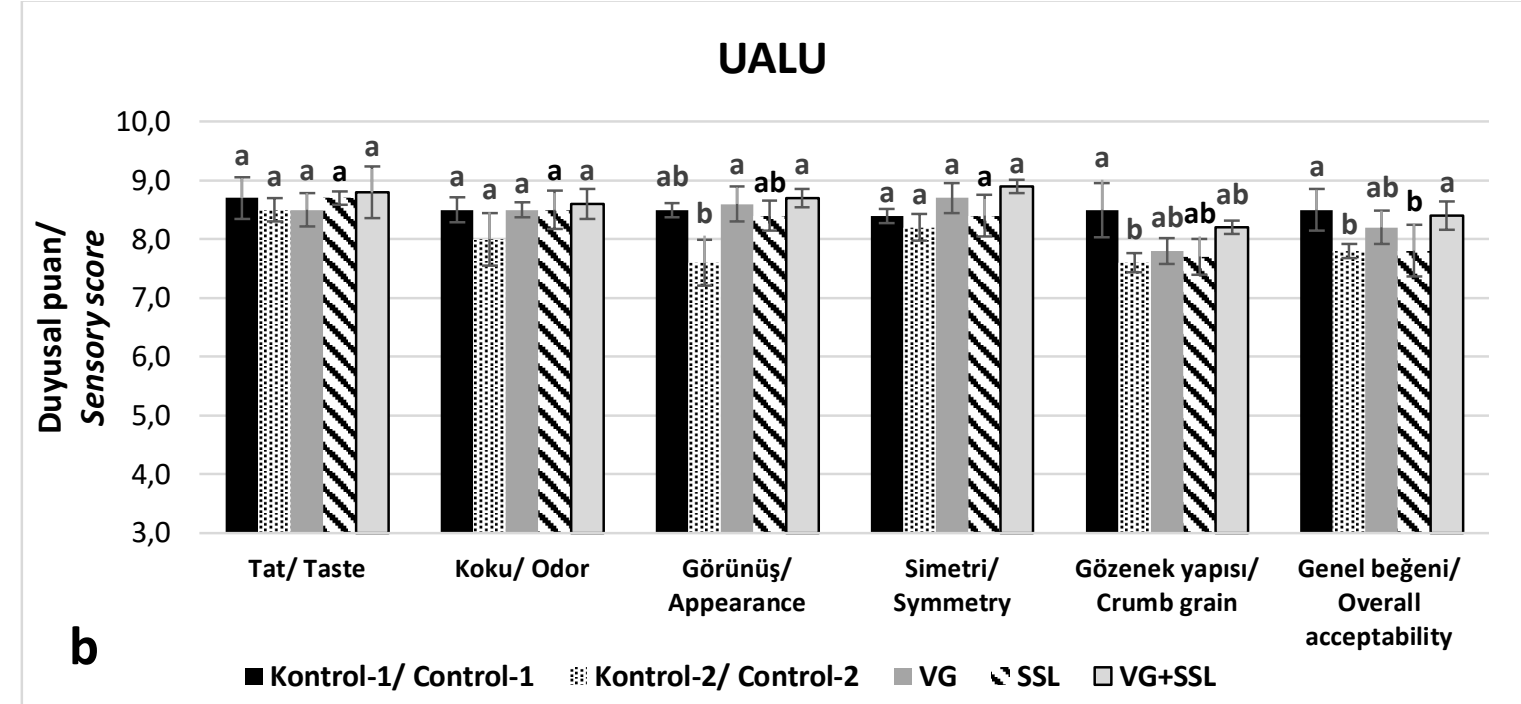

Şekil 2. GALU (a) ve UALU (b) içeren ekmek örneklerine ait duyusal analiz sonuçları Figure 2. Sensory analysis results of bread samples containing GALU (a) and UALU (b)

\section{SONUÇ}

$\mathrm{Bu}$ çalışmada; vital gluten, SSL ve vital gluten+SSL kullanımının lüpen unu ve DN içeren ekmeğin fiziksel, tekstürel ve duyusal özellikleri üzerine etkilerinin araştırılması amaçlanmıştır. $\% 10$ lüpen unu+\%10 DN içeren ekmek formülasyonuna (Kontrol-2) ilave edilen kaktı maddelerinin (vital gluten, SSL ve vital gluten+SSL), Kontrol-2 ekmeğinin kabuk $L^{*}$ ve $b^{*}$ değerleri ile iç $L^{*}$ ve $a^{*}$ değerlerinde önemli $(P$ $>0.05)$ bir değişikliğe sebep olmadı̆ 1 görülmüştür. Lüpen unu çeşidi olarak UALU ve katk1 çeşidi olarak vital gluten+SSL kombinasyonunun kullanımı, ekmek örneklerinin hacim, spesifik hacim, sikilik ve sertlik değerlerinde daha olumlu sonuç vermiştir. Hem GALU hem de UALU ile hazırlanan ekmek örneklerinde, vital gluten ve vital gluten+SSL katkılarının $\% 100$ buğday unu ekmeğine (Kontrol-1) yakın tat, koku, görünüş, simetri gözenek yapısı ve genel beğeni puanları sağladığı belirlenmiştir.

\section{TEŞEKKÜR}

$\mathrm{Bu}$ çalışma, Elif Yaver tarafindan hazırlanan doktora tezinin bir kısmından üretilmiştir. Çalışmada kullanılan lüpen unlarının elde edilmesinde uygulanan acilik giderme ve stabilizasyon prosesleri, 119O071 no'lu TÜBİTAK projesi kapsamında desteklenmiştir.

\section{ÇIKAR ÇATIŞMASI BEYANI}

Yazarlar, çıkar çatışması olmadığını beyan ederler.

\section{YAZAR KATKILARI}

NB, danışman olarak; araştırmanın planlanması, metodolojisi, makalenin incelenmesi ve düzenlenmesinde katkı sağlamıştır. $E Y$; laboratuvar çalışmalarının yürütülmesini ve makalenin yazımını gerçekleştirmiştir. Yazarlar makalenin son halini okumuş ve onaylamışlardır.

\section{KAYNAKLAR}

AACC (1990). Approved Methods of the American Association of Cereal Chemists, (8th ed.). St. Paul, MN, USA: AACC.

AACC (2000). Approved Methods of the American Association of Cereal Chemists, (10 th ed.). St. Paul, MN, USA: AACC.

Asp, N.G., Bjorck, I. (1992). Resistant starch. Trends Food Sci Technol, 3, 111-114, doi: 10.1016/0924-2244(92)90153-N.

Belski, R., Mori, T.A., Puddey, I.B., Sipsas, S., Woodman, R.J., Ackland, T.R., Beilin, L.J., Dove, N.B., Jayasena, V., Hodgson, J.M. (2011). Effects 
of lupin-enriched foods on body composition and cardiovascular disease risk factors: A 12 month randomized controlled weight loss trial. Int J Obes, 35, 810-819, doi: 10.1038/ijo.2010.213.

Birkett, A.M., Mathers, J.C., Jones, G.P., Walker, K.Z., Roth, M.J., Muir, J.G. (2000). Changes to the quality and processing of starchy foods in a Western diet can increase polysaccharides escaping digestion and improve in vitro fermentation variables. Br J Nutr, 84, 63-72, doi: 10.1017/S0007114500001240.

Boz, H. (2008). Farklı doğal bitkisel katkıların organik ekmek üretiminde kullanılması ve kalite üzerine etkileri. Atatürk Üniversitesi Fen Bilimleri Enstitüsü Yüksek Lisans Tezi, Erzurum, Türkiye, $93 \mathrm{~s}$.

Brown, I.L., McNaught, K.J., Ganly, R.N., Conway, P.L., Evans, A.J., Topping, D.L., Wang, X. (1996). Probiotic compositions. Intl. Patent WO 96/ 08261/ A1. Issued Mar 21, 1996.

Coda, R., Varis, J., Verni, M., Rizzello, C.G., Katina, K. (2017). Improvement of the protein quality of wheat bread through faba bean sourdough addition. LWT - Food Sci Technol, 82, 296-302, doi: 10.1016/j.lwt.2017.04.062.

Curti, E., Carini, E., Tribuzio, G., Vittadini, E. (2014). Bread staling: Effect of gluten on physicochemical properties and molecular mobility. LWT - Food Sci Technol, 59, 418-425, doi: 10.1016/j.lwt.2014.04.057.

Day, L., Augustin, M.A., Batey, I.L., Wrigley, C.W. (2006). Wheat-gluten uses and industry needs. Trends Food Sci Technol, 17, 82-90, doi: 10.1016/j.tifs.2005.10.003.

Dervas, G., Doxastakis, G., HadjisavvaZinoviadi, S., Triantafillakos, N. (1999). Lupine flour addition to wheat flour doughs and effect on rheological properties. Food Chem, 66, 67-73, doi: 10.1016/S0308-8146(98)00234-9.

Dizlek, H., Çimer, H., Altan, A. (2013). Vital buğday gluteninin ve L-askorbik asidin buğday kepekli ekmeklerin bazı nitelikleri üzerine etkileri. Gida, 38(2), 87-94.

Düzgüneş, O., Kesici, T., Kavuncu, O., Gürbüz, F. (1987). Arastırma ve Deneme Metodlar (Istatistiksel
Metodlar-II), Ankara Üniversitesi, Ziraat Fakültesi Yayınları, Yayın No: 1021, Ankara.

Elgün, A., Türker, S., Bilgiçli, N. (2001). Tahıl ve Ürülerinde Analitik Kalite Kontrolü, Konya Ticaret Borsası Yayınlan1, Yayın No: 2, Konya.

Englyst, H.N., Kingman, S.M., Cummings, J.H. (1992). Classification and measurement of nutritionally important starch fractions. Eur J Clin Nutr, 46, 33-50.

Francis, F.J. (1998). Colour analysis, in: Food Analysis, S.S. Nielsen (Ed.), An Aspen Publishers, Maryland, Gaithersnurg, USA, pp. 599-612.

Gomes-Ruffi, C.R., Cunha, R.H., Almeida, E.L., Chang, Y.K., Steel, C.J. (2012). Effect of the emulsifier sodium stearoyl lactylate and of the enzyme maltogenic amylase on the quality of pan bread during storage. LWT-Food Sci Technol, 49, 96-101, doi: 10.1016/j.lwt.2012.04.014.

Güdük, H. (2016). Misırlı ekmeklerde misır unu seviyesi ve katkı kullanımının kalite üzerine etkisi. Atatürk Üniversitesi Fen Bilimleri Enstitüsü Gıda Mühendisliği Anabilim Dalı Yüksek Lisans Tezi, Erzurum, $104 \mathrm{s.}$

Higgins, J.A., Dana, H.R., Donahoo, W.T., Brown, I.L., Bell, M.L., Bessesen, D.H. (2004). Resistant starch consumption promotes lipid oxidation. Nutr Metab, 1, 1-8, doi: 10.1186/17437075-1-8.

Hooda, S., Jood, S. (2005). Organoleptic and nutritional evaluation of wheat biscuits supplemented with untreated and treated fenugreek flour. Food Chem, 90(3), 427-435, doi: 10.1016/j.foodchem.2004.05.006.

Jiang, X., Chang, M., Wang, X., Jin, Q., Wang, X. (2014). Effect of ultrasound treatment on oil recovery from soybean gum by using phospholipase C. J Clean Prod, 69, 237-242, doi: 10.1016/j.jclepro.2014.01.060.

Johnson, S.K., Mcquillan, P.L., Sin, J.H., Ball, M.J. (2003). Sensory acceptability of white bread with added Australian sweet lupin (Lupinus angustifolius) kernel fibre and its glycaemic and insulinaemic responses when eaten as a breakfast. $J$ Sci Food Agric, 83, 1366-1372, doi: 10.1002/jsfa.1552. 
Khaleel, M.L., Sharoba, A.M., El-Desouky, A.I., Mohamed, M.H. (2018). Use of some emulsifiers to improve the quality of pan bread product. Tikrit Joumal for Agricultural Sciences, 18, 150-161.

Kim, Y.-J., Lee, J.-H., Choi, M.-J., Choi, D.-R., Lee, S.-K. (2013). Effects of vital wheat gluten on quality characteristics of white pan bread containing resistant starch. J Korean Soc Food Sci Nutr, 42(1), 76-82, doi: 10.3746/jkfn.2013.42.1.076.

Krog, N. (1981). Theoretical aspects of surfactants in relation to their use in breadmaking. Cereal Chem, 58, 158-164.

Lee, Y.P., Mori, T.A., Puddey, I.B., Sipsas, S., Ackland, T.R., Beilin, L.J., Hodgson, J.M. (2009). Effects of lupin kernel flour-enriched bread on blood pressure: A controlled intervention study. Am J Clin Nutr, 89, 766-772, doi: 10.3945/ajen.2008.26708.

Li, H., Wang, J., Pan, L., Lu, Q. (2019). Effect of amino and thiol groups of wheat gluten on the quality characteristics of Chinese noodles. J Food Sci Technol, 56(6), 2825-2835, doi: 10.1007/s13197-019-03688-8.

Liu, W., Brennan, M., Serventi, L., Brennan, C. (2017). Buckwheat flour inclusion in Chinese steamed bread: Potential reduction in glycemic response and effects on dough quality. Eur Food Res Technol, 243, 727-734, doi: 10.1007/s00217-016-2786-x.

Martin, M.L., Zeleznak, K.J., Hoseney, R.C. (1991). A mechanism of bread firming, I. Role of starch swelling. Cereal Chem, 68, 498-503.

Meyer, K.A., Kushi, L.H., Jacobs, D.R., Slavin, J., Sellers, T.A., Folsom, A.R. (2000). Carbohydrates, dietary fiber, and incident type 2 diabetes in older women. Am J Clin Nutr, 71, 921-930, doi: 10.1093/ajen/71.4.921.

Mohammed, M.A., Mohamed, E.A., Yagoub, A.E.A., Mohamed, A.R., Babiker, E.E. (2017). Effect of processing methods on alkaloids, phytate, phenolics, antioxidants activity and minerals of newly developed lupin (Lupinus albus L.) cultivar. J Food Process Preserv, 41, 1-9, doi: 10.1111/jfpp.12960.
Morais, M.B., Feste, A., Miller, R.G., Lifichitz, C.H. (1996). Effect of resistant starch and digestible starch on intestinal absorption of calcium, iron and zinc in infant pigs. Pediatr Res, 39, 872-876, doi: 10.1203/00006450-19960500000022 .

Oomah, B.D., Tiger, N., Olson, M., Balasubramanian, P. (2006). Phenolics and antioxidative activities in narrow-leafed lupins (Lupinus angustifolius L.). Plant Foods Hum Nutr, 61, 91-97, doi: 10.1007/s11130-006-0021-9.

Ortolan, F., Steel, C.J. (2017). Protein characteristics that affect the quality of vital wheat gluten to be used in baking: A review. Compr Rev Food Sci Food Saf, 16, 369-381, doi: 10.1111/15414337.12259 .

Özkaya，B., Özkaya, H. (1992). Misır katkıl1 unların teknolojik özelliklerine vital gluten ve SSL'in (Na-Stearoyl-2-Lactilate) etkileri. Grda, 17(6), 419-426.

Pomeranz, Y. (1987). Modern Cereal Science and Technology. VCH Publishers, Washington.

Sanchez, D.B.O., Puppo, M.C., Anon, M.C., Ribotta, P.D., Leon, A.E., Tadini, C.C. (2014). Effect of maize resistant starch and transglutaminase: A study of fundamental and empirical rheology properties of pan bread dough. Food Bioproc Tech, 7, 2865-2876, doi: 10.1007/s11947-013-1246-x.

Sanz-Penella, J.M., Wronkowska, M., SoralSmietana, M., Collar, C., Haros, M. (2010). Impact of the addition of resistant starch from modified pea starch on dough and bread performance. Eur Food Res Technol, 231, 499-508, doi: 10.1007/s00217-010-1294-7.

Sirtori, C.R., Lovati, M.R., Manzoni, C., Castiglioni, S., Duranti, M., Magni, C., Morandi, S., D'agostina, A., Arnoldi, A. (2004). Proteins of white lupin seed, a naturally isoflavone-poor legume, reduce cholesterolemia in rats and increase LDL receptor activity in HepG2 cells. $J$ Nutr, 134, 18-23, doi: 10.1093/jn/134.1.18.

Sluimer, P. (2005). Principles of breadmaking: Functionality of raw materials and process steps, 
St. Paul: The American Association of Cereal Chemists, Inc.

van Steertegem, B., Pareyt, B., Brijs, K., Delcour, J.A. (2013). Impact of mixing time and sodium stearoyl lactylate on gluten polymerization during baking of wheat flour dough. Food Chem, 141, 4179-4185, doi: 10.1016/j.foodchem.2013.07.017.

Villarino, C.B.J., Jayasena, V., Coorey, R., Chakrabarti-Bell, S., Foley, R., Fanning, K., Johnson, S.K. (2015). The effects of lupin (Lupinus angustifolius) addition to wheat bread on its nutritional, phytochemical and bioactive composition and protein quality. Food Res Int, 76, 58-65, doi: 10.1016/j.foodres.2014.11.046.

Willhoft, E.M.A. (1973). Mechanism and theory of staling of bread and baked goods and associated changes in textural properties. $J$ Texture Stud, 4, 292-322, doi: 10.1111/j.17454603.1973.tb00844.x.

Wong, J.M., de Souza, R., Kendall, C.W., Emam, A., Jenkins, D.J. (2006). Colonic health:
Fermentation and short chain fatty acids. J Clin Gastroenterol, 40, 235-243.

Yang, F., Liu, X., Ren, X.E., Huang, Y., Huang, C., Zhang, K. (2018). Swirling cavitation improves the emulsifying properties of commercial soy protein isolate. Ultrason Sonochem, 42, 471-481, doi: 10.1016/j.ultsonch.2017.12.014.

Yaver, E. (2021). Raf ömrü uzun lüpen unu üretimi ve besinsel-fonksiyonel özellikleri geliştirilmiş makarna ve ekmek üretiminde kullanımı. Necmettin Erbakan Üniversitesi Fen Bilimleri Enstitüsü Gıda Mühendisliği Anabilim Dalı Yayımlanmamış Doktora Tezi, Konya, Türkiye, 314 s.

Yıldız, G. (2009). Karabuğday (Fagopyrum esculentum Moench) ununun geleneksel Türk ekmeklerinde kullanılma imkanları üzerine araştırmalar. Selçuk Üniversitesi Fen Bilimleri Enstitüsü Gıda Mühendisliği Anabilim Dalı Yüksek Lisans Tezi, Konya, Türkiye, 124 s. 